\title{
Lights out, let's move about: locomotory activity patterns of Wagner's gerbil from the desert of Saudi Arabia
}

\author{
A.N. Alagaili', O.B. Mohammed', N.C. Bennett ${ }^{1,2} \&$ M.K. Oosthuizen ${ }^{2 *}$ \\ ${ }^{1}$ KSU Mammals Research Chair, Department of Zoology, College of Science, King Saud University, \\ P.O. Box 2455, Riyadh 11451, Saudi Arabia \\ ${ }^{2}$ Mammal Research Institute, Department of Zoology \& Entomology, University of Pretoria, \\ Pretoria, 0002 South Africa \\ Received 28 February 2012. Accepted 26 June 2012
}

\begin{abstract}
We investigated the circadian activity rhythm in the little-studied Wagner's gerbil (Gerbillus dasyurus) from the Raydah Protected Area, southwestern Saudi Arabia. In order to assess whether these animals possess an endogenous rhythm of locomotor activity that entrains to the light:dark cycle, they were subjected to three distinct light cycles: an LD cycle (12 h light/12 h dark), a DD cycle (constant darkness) and a DL light cycle (an inverse of the LD light cycle). All eight individuals studied exhibited entrainment of their activity to the light cycles. Under LD, the total percentage of activity during the dark phase was $93.7 \pm 1.8 \%$. Activity was distributed throughout the night (mean peak activity 22:46 $\pm 0: 14$ ). All eight animals expressed distinct endogenous free-running rhythms of locomotor activity (mean $\tau=23: 55 \pm$ $0: 36)$. During constant darkness, animals still displayed more activity during the subjective night $(75.6 \pm 0.4 \%)$. Under the DL light cycle, the total percentage of activity was $92.7 \pm 1.8 \%$ during the dark phase. In conclusion, the daily locomotor activity rhythm of Wagner's gerbil is strongly entrained by the light:dark cycle with the most activity concentrated during the night and consequently this desert-dwelling mammal may thus be considered truly nocturnal.
\end{abstract}

Key words: circadian rhythm, light:dark cycle, locomotor activity, Saudi Arabia, Wagner's gerbil.

\section{INTRODUCTION}

Hot, dry deserts are notoriously difficult to survive in, being characterized by extreme ambient temperatures, little or no rainfall, intense solar radiation and a generally low primary productivity (Schmidt-Nielsen 1964; Degen 1997). As a consequence, mammals occurring in these environments are prone to desiccation and have to regulate both their energy and water balance tightly (Macfarlane 1968). Given the harsh conditions operational throughout the day it is not unreasonable to expect that the majority of the locomotor activity of mammals occurring in these areas to be confined to the night when temperatures are more equable and water balance can be maintained. A nocturnal lifestyle would also assist in the avoidance of a number of diurnal predators (Demas et al. 2001).

A number of variables of the natural environment exhibit rhythmically with chronological time. Physiological rhythms of organisms that repeat themselves on a daily basis are termed circadian rhythms and are established when the biological clock and chronological time are synchronized (Aschoff 1981; Goldman 1999; Froy 2007). The light:dark cycle is by far the most predictable environmental time cue and acts as a primary synchronizer or zeitgeber of circadian rhythms (Pittendrigh \& Minis 1964; Quintero et al. 2003; Skene et al. 1999). Circadian rhythms are typical of all eukaryotic organisms and are predominantly under endogenous control (Daan \& Aschoff 1981; Refinetti 2007). An organism that is devoid of input from external time cues and maintained under constant conditions, will express its own innate circadian rhythm that will free-run with a period $(\tau)$ of close to $24 \mathrm{~h}$ (Aschoff 1981; Szeisler et al. 1999; Refinetti 2006). Free-running is characteristic of a rhythm generated endogenously by a biological clock, which in mammals is generated in the suprachiasmatic nucleus (Stephan \& Zucker 1972; Okamura et al. 2002; Froy 2007). The free-running period of an organism is usually species-specific (Pittendrigh \& Daan 1974; Aschoff 1981; Refinetti 2006).

Wagner's gerbil is a solitary, burrowing species that occurs in a variety of arid habitats including 
desert, semi-desert and rocky habitats in hill country (Amori et al. 2008). It is widely distributed in the steppe deserts in the Arabian Peninsula feeding on the seeds of herbs (Harrison \& Bates 1991), the extreme north of the Sinai Peninsula (Haim \& Tchernov 1974) the steppes and arid regions of the northern Arabian Peninsula (Zahavi \& Wahrman 1957) as well as Egypt, the Lebanon and Turkey (Zahavi \& Wahrman 1957; Amori et al. 2008). Wagner's gerbil is able to thermoregulate extremely well in both hot and cold environments (Haim 1987). It is this property that may account for the wide distribution of this species in both arid and mesic environments (Harrison \& Bates 1991).

We examined and described the basic locomotor activity patterns of Wagner's gerbil from the rocky desert of southwestern Saudi Arabia. The aim was to determine whether a circadian rhythm of locomotor activity could entrain to a controlled light:dark cycle and determine the period of the free-running rhythm $(\tau)$ under constant conditions. In addition, we investigated whether the gerbil could shift its activity according to an inverse in the light cycle to determine whether the transition between light and dark triggers activity or whether they are truly nocturnal. We predicted that Gerbillus dasyurus will exhibit a preference for the dark phase of the light/dark cycle and that the free-running period would be less than $24 \mathrm{~h}$ as it tends to be for nocturnal mammals according to Aschoff's rule (Aschoff 1981).

\section{MATERIALS \& METHODS}

\section{General}

Eight Wagner's gerbils (Gerbillus dasyurus), five males and three females (mean \pm S.E.M.: $29.3 \pm$ $0.5 \mathrm{~g}$ ) were collected in the mountains near Abha City, in southwestern Saudi Arabia $\left(18^{\circ} 00^{\prime} \mathrm{N}\right.$, $\left.24^{\circ} 46^{\prime} \mathrm{E}\right)$. The elevation of the trapping area is more than $2000 \mathrm{~m}$, and temperatures moderate $\left(3-33^{\circ} \mathrm{C}\right.$, www.wunderground.com). The gerbils were trapped in August 2011 using cage live traps (Strauss et al. 2008) baited with bread and peanut butter. After capture, the animals were transported to the animal facility at the Department of Zoology, College of Science, King Saud University, Riyadh, Saudi Arabia, where the experimental procedures were carried out. Experiments commenced approximately four weeks after capture. The experiments and procedure were evaluated by the Animal Use and Care Committee of the University of Pretoria, ethics clearance number EC013-12.
The gerbils were housed individually in plastic terraria $(50 \times 40 \times 40 \mathrm{~cm})$ and provided with wood shavings and plastic hides as nesting material. Food and water was provided ad libitum, and a few drops of multivitamins were added to the drinking water. Animals were fed on pelleted poultry food from the Arabian Agricultural Services Company (Arasco, Riyadh, Saudi Arabia) every 14 days at the end of each cycle. The diet was supplemented with carrots and cucumber when light cycles were changed. During the feeding times the general health and condition of the animals was monitored. The experimental room was temperature controlled at $25 \pm 1^{\circ} \mathrm{C}$ and the room was light controlled which enabled us to create different light regimes throughout the experimental period.

\section{Experimental procedures}

Animals were maintained on a 12L:12D cycle (6:00-18:00 L) for 14 days to determine how well they entrain to light cycles. This was followed by a 14-day DD cycle in order to determine whether the gerbils have endogenous free-running rhythms of locomotor activity. Subsequently the lights were switched back to the original 12L: 12D cycle to re-entrain the animals, after which the light cycle was inversed to investigate whether and how fast the animals change their activity according to the new light cycle.

\section{Activity measurements}

An infrared captor (Quest PIR internal passive infrared detector; Elite security products (ESP), Electronic lines, U.K.) was fitted in the inner side of the cage cover which was made of chicken-mesh where the animal was housed. These sensors were placed in the middle of each cage to detect any movement that the animal made in any area of the cage. A reading was taking once every minute and the activity measurements were captured by the program Vital View on a computer system (Vital View ${ }^{\mathrm{TM}}$, Minimitter Co., Inc., Sunriver, OR, U.S.A.; www.minimitter.com).

\section{Data analyses}

Activity was depicted as double-plotted actograms with Actiview Biological Rhythm Analyses 1.2 software (Minimitter Co., Inc., Sunriver, OR, U.S.A.; www.minimitter.com) so that activity patterns could be visualized. The phase angle was calculated for each animal. To determine peak activity times, activity profiles were generated in Clocklab 
(ClockLab TM, Actimetrics, Evanston, Il. U.S.A.). Microsoft Excel Macro's (Microsoft ${ }^{\circledR}$ Office Excel ${ }^{\circledR}$ 2007) were used to determine percentage activity during the day and night phase for each light regime per animal. The circadian period of locomotor activity rhythms during DD were determined using Clocklab. To determine whether the amount of activity during the different phases was significantly different from one another, Statistica $9.0\left({ }^{\oplus}\right.$ StatSoft, Inc. 1984-2009) was employed. Owing to small sample sizes, non-parametric statistics were used for all calculations.

\section{RESULTS}

\section{L:12D}

All eight Wagner's gerbils entrained their activity to the $12 \mathrm{~L}: 12 \mathrm{D}$ cycle presented. All animals showed a preference for activity during the dark phase of the light cycle, with a mean ( \pm S.E.M.) percentage of activity during the dark phase of $93.7 \pm 1.8 \%$. Activity was distributed throughout the night (mean \pm S.E.M. peak activity 22:46 \pm 00:14), although several of the animals displayed spikes in activity around the transition periods between light and dark. Little or no activity was displayed during the light phase.

All individuals displayed clear onsets, the mean phase angle ( \pm S.E.M.) was $13 \pm 3$ min after the transition from light to dark. Six animals also exhibited clear offsets with a mean phase angle ( \pm S.E.M.) of $20 \pm 21 \mathrm{~min}$ before commencement of the light phase. The offset times of individual animals showed more variability than onset times.

An individual was categorized as nocturnal when more than $70 \%$ of activity was displayed during the night. All eight Wagner's gerbils displayed more than $85 \%$ of their activity during the dark phase of the light cycle, thus they can be classified as nocturnal with confidence (Fig. 1).

\section{DD}

All gerbils exhibited free-running rhythms in constant darkness, with the exception of one, the endogenous rhythms were slightly shorter than $24 \mathrm{~h}(n=8$, mean \pm S.E.M. $=23: 55 \pm 0: 36)$. During the constant darkness cycle, animals still displayed more activity during the subjective night (75.6 \pm $0.4 \%$ ) however, compared to the LD1 cycle, a significantly higher percentage of activity was exhibited during subjective day (Wilcoxon matched paired test $Z=2.52, T=0, n=8, P=$ 0.011; Fig. 2).

\section{LD and inversed LD}

Following the constant dark cycle, all animals re-entrained to the 12L:12D light cycle. The mean percentage ( \pm S.E.M.) of activity during the dark phase increased again to $92.7 \pm 1.8 \%$. Upon inversion of this light cycle, all animals shifted their activity to coincide with the dark phase of the new cycle. The onset of activity shifted immediately in all individuals however, the offset re-entrained more gradually, and took up to six days to fully re-entrain to the light cycle (Fig. 3). The mean percentage ( \pm S.E.M.) of activity displayed during the dark phase of the inversed light cycle was $92.8 \pm$ $1.6 \%$, and it is not significantly different from the amount of activity during the dark phase of LD2 (Wilcoxon matched paired test $Z=8, T=18, n=8$, $P=1$; Fig. 3).

\section{DISCUSSION}

Gerbils are rodents and belong to the subfamily Gerbillinae that comprises about 90 species. They occur widespread in Africa, Asia, India and the Middle East, mostly in hot, arid regions (MacDonald 2006). Apart from the large temperature variations, the low rainfall and intense solar radiation increase the risk of dehydration even further for small mammals that have to regulate energy and water balance very carefully (Schmidt Nielsen 1997). However, desert mammals are well adapted to these extreme environmental conditions and adopt distinct activity patterns to enhance their survival in their natural environments. Most small desert mammals which occur in hot, dry deserts are fossorial and occupy burrow systems in the heat of the day. With the onset of night, the ambient temperature drops to a more hospitable level, and animals can emerge from their underground shelters to forage (Demas et al. 2001).

The Wagner's gerbil has a wide geographical range in Saudi Arabia, where in some areas day temperatures can reach up to $45^{\circ} \mathrm{C}$ while night temperatures drop to $4^{\circ} \mathrm{C}$ (Al-Helal 2003). In the laboratory, Wagner's gerbil appears to restrict its activity to being entirely nocturnal. It entrains its daily locomotor activity to commence after the transition from light to dark and ceases activity before the next light cycle. Very little activity was observed during the light phase of the light cycle. Previously, it has been reported that around 80\% of Wagner's gerbils display crepuscular activity when exposed to a running wheel, the remaining 20\% exhibited nocturnal activity (Demas et al. 2001). Several studies have been conducted on the locomotor activity 


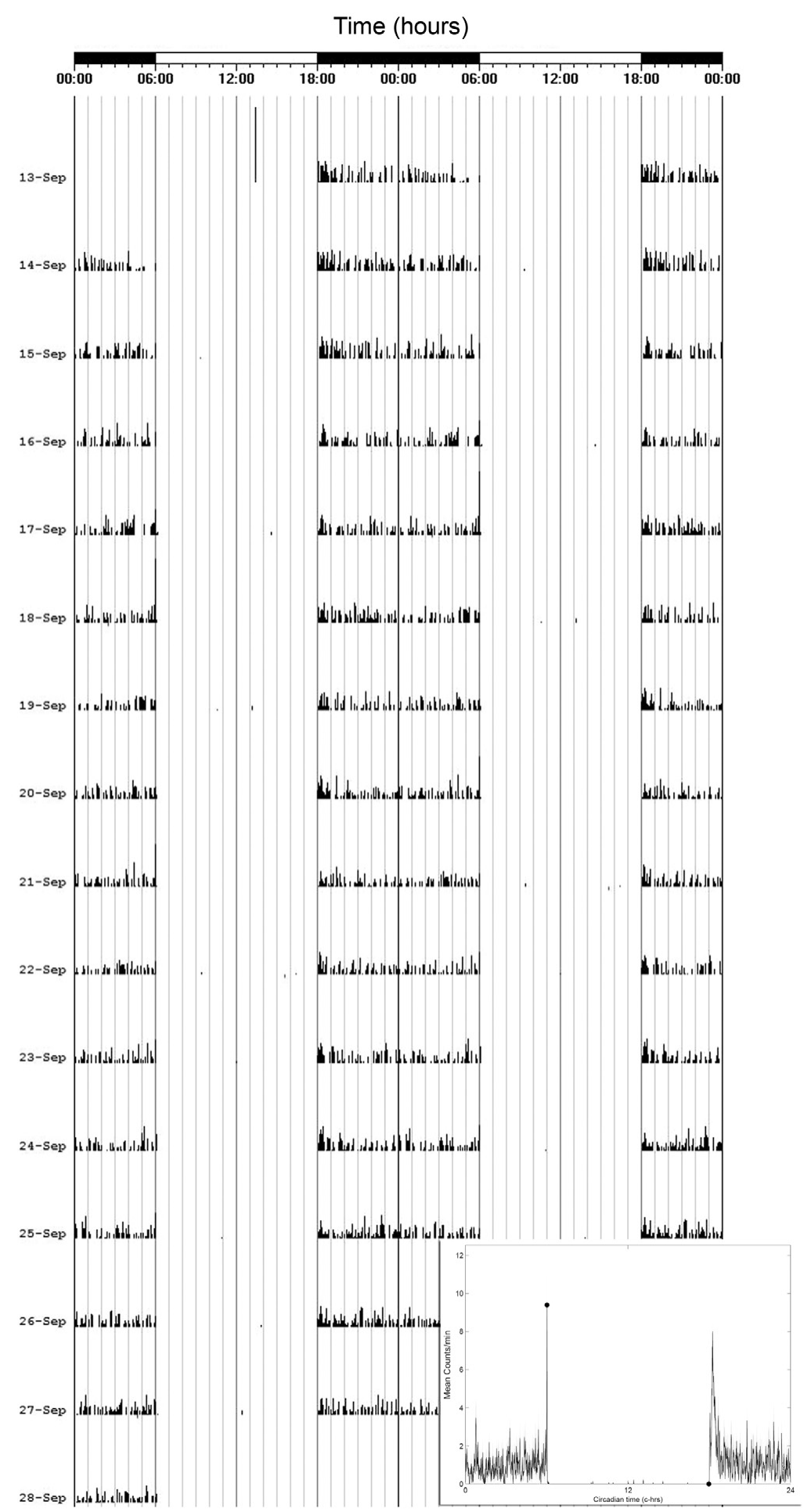

Fig. 1. A double-plotted actogram of a typical locomotor activity rhythm of a Wagner's gerbil. The bar at the top of the actogram illustrates when lights were on and off. Inset: an activity profile of the same animal is presented to illustrate the distribution of activity over the 24 -h period. 
Time (hours)

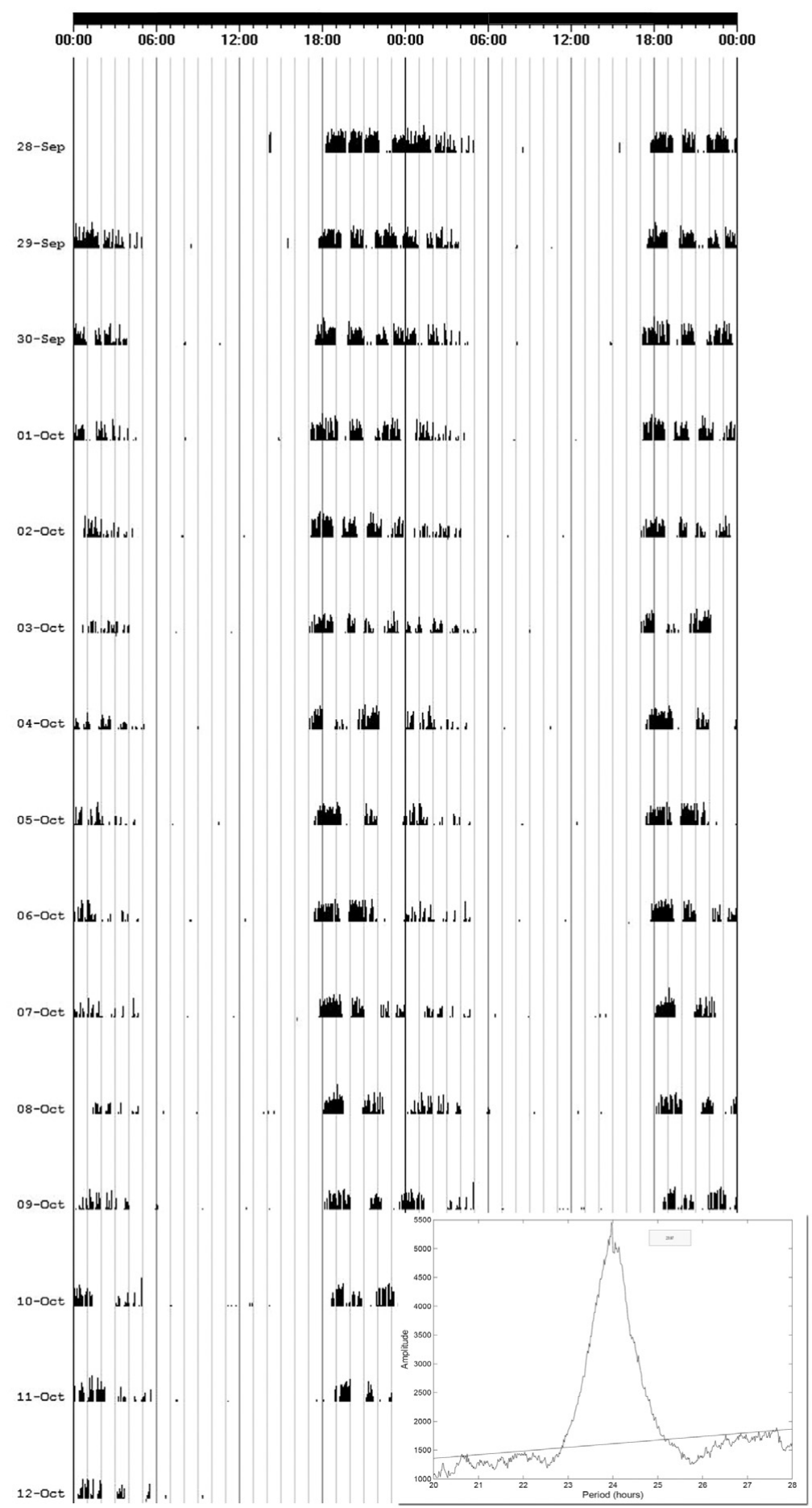

Fig. 2. An example of an actogram from a Wagner's gerbil during constant darkness, showing an endogenous rhythm slightly shorter than $24 \mathrm{~h}$. Inset: periodogram of the same individual illustrating the 23.97-h period of the endogenous rhythm. 
Time (hours)

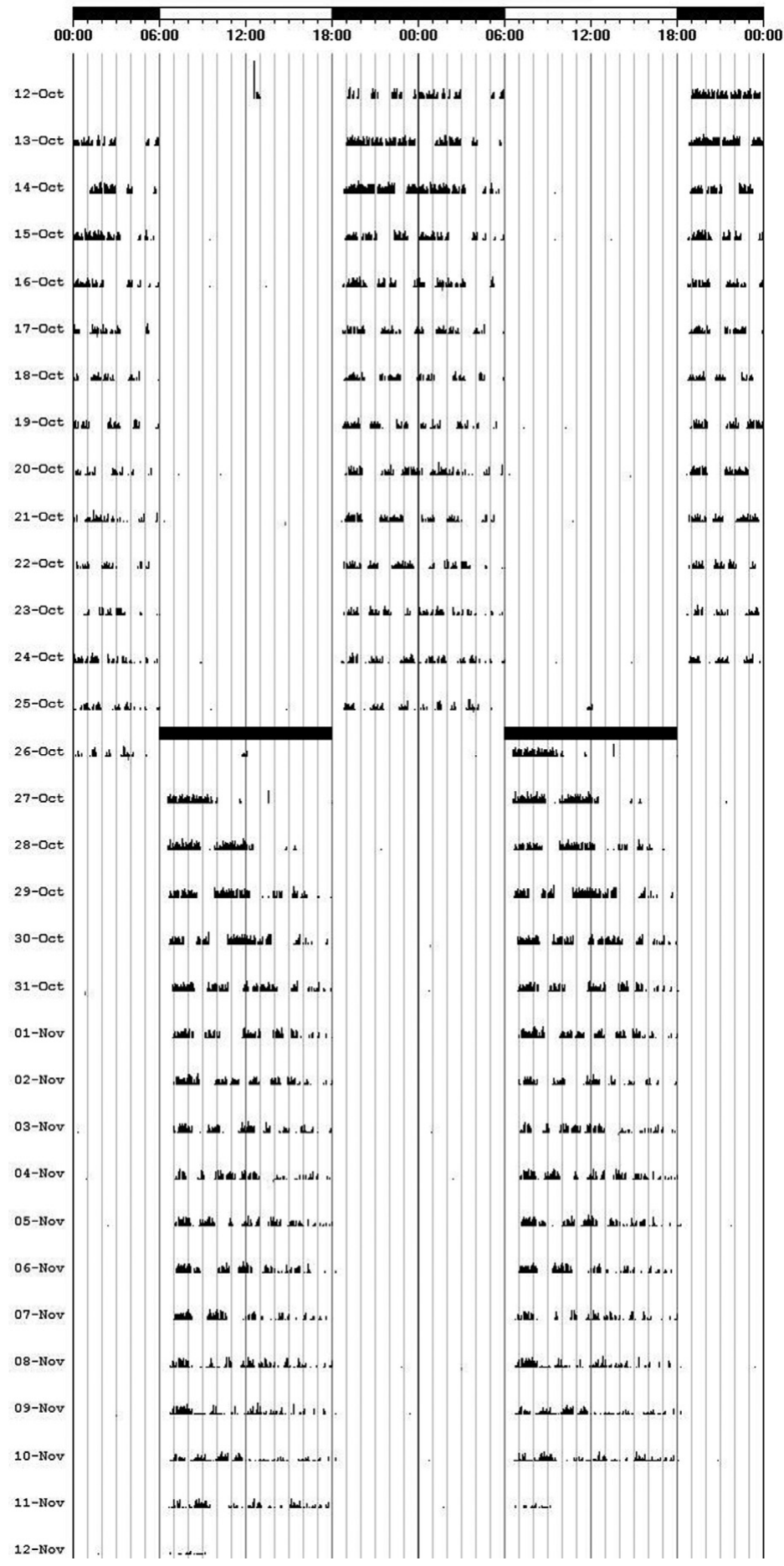

Fig. 3. An actogram showing the transition between LD2 and DL, where the onsets of activity shifted immediately according to the changed cycle while the offsets re-entrained more gradually. Black bars indicate when lights were switched off. 
patterns of the Mongolian gerbil (Meriones unguiculatus), with contradicting results (for review see Bartness \& Albers 2000). However, in laboratory conditions with a square wave lighting regime similar to our experiment, two peaks of activity were observed, one during the first half of the day and another during the light:dark transition period. When a running wheel was available, all animals switched their activity to nocturnal (Weinert et al. 2007). Two other species of gerbil (Gerbillus andersoni and G. pyramidum) also displayed nocturnal wheel running activity (Demas et al. 2001). It has been suggested that access to a running wheel increases nocturnal activity (Weinert et al. 2007). Although it makes sense for desert dwelling rodents to confine their activity to darkness and seek refuge in their burrows during the heat of the day, it seems that the amount of activity that these desert animals display during the night is determined by the conditions under which they are tested.

Free-running circadian rhythms have so far not been described for Wagner's gerbil. In our experiment, all gerbils displayed free-running activity rhythms close to $24 \mathrm{~h}$, the majority of the animals showed a $\tau$ shorter than $24 \mathrm{~h}$ but some did display a $\tau$ longer than $24 \mathrm{~h}$. In general, the on and offsets of activity became less precise during constant conditions; however, we did not find the amount of intraspecific variability in free-running length encountered in the Mongolian gerbil by Klaus et al. (2000). A high sensitivity to non-photic cues was suggested to explain the variability; however, it appears that Wagner's gerbil relies more heavily on photic cues to synchronize their endogenous rhythms.

All animals inverted their activity profiles when the light cycle was inverted, suggesting that the gerbils do not merely entrain to the transition of light and dark, but show a definite preference to be active during a specific phase of the light cycle. The onset of activity changed immediately to the new cycle, whereas duration of active time gradually increased until the offset was at the end of the dark period. After a 12-h phase shift, the gerbils re-entrained their activity by delay phase shifts. The time to completely re-entrain to a reversed light cycle varies from species to species. In this case re-entrainment was completed in 4-6 cycles. The rate of re-entrainment depends on a number of internal and external factors such as the strength of the zeitgeber, the period and phase response curve of the pacemaker and experimental protocol
(Aschoff et al. 1975; Pittendrigh \& Daan 1976), which renders it challenging to compare between different studies and species.

Our study provides convincing evidence for a distinctly nocturnal activity pattern for Wagner's gerbil, Gerbillus dasyurus, in stable, square-wave light, laboratory conditions and quantifies for the first time the free-running period for the endogenous rhythm of locomotor activity.

\section{ACKNOWLEDGEMENTS}

We extend our appreciation to the Deanship of Scientific Research at the King Saud University for funding the work through the research group project No. RGP_VPP_020. We thank HH Prince Bandar Bin Mohammed Bin Saud, Secretary General, Saudi Wildlife Authority, for permission to trap the animals in the Raydah Protected Area in southwestern Saudi Arabia. NCB gratefully acknowledges support from the Visiting Professors Programme of King Saud University to undertake research in Saudi Arabia.

\section{REFERENCES}

AL-HELAL, I.M. (2003). Environmental control for poultry buildings in Riyadh area of Saudi Arabia. Journal of the King Saud University Agricultural Science 16: 87-102.

AMORI, G., HUTTERER, R., KRYŠTUFEK, B., YIGIT, N., MITSAIN, G., MUNOZ, L.J.P. \& AULAGNIER, S. 2008. Gerbillus dasyurus. In: IUCN 2011. IUCN Red List of Threatened Species. Version 2011.2. Online at: www.iucnredlist.org.

ASCHOFF, J., HOFFMANN, K., POHL, H. \& WEVER, R. 1975. Re-entrainment of circadian rhythms after phase-shifts of the zeitgeber. Chronobiologia 2: 23-78.

ASCHOFF, J. 1981. Free-running and entrained circadian rhythms. In: Handbook of Behavioural Neurobiology, (ed.) J. Aschoff, Vol. 4, pp. 81-93. Plenum Press, New York.

BARTNESS, T.J. \& ALBERS, H.E. 2000. Activity patterns and the biological clock in mammals. In: Activity Patterns in Small Mammals, (eds) S. Halle \& N.C. Stenseth, pp. 23-47. Springer-Verlag, Heidelberg.

DEGEN, A.A. 1997. Ecophysiology of Small Desert Mammals. Springer Verlag, Germany.

DEMAS, G.E., El-BAKRY, H.A., MINTZ, E.M., ZAHARI, W.M. \& BARTNESS, T.J. 2001. Wheel-running activity patterns of five species of desert rodents. Biological Rhythms Research 32: 1-16.

DAAN, S. \& ASCHOFF, J. 1981. The entrainment of circadian rhythms. In: Handbook of Behavioural Neurobiology; Circadian Clocks, (eds) J.S. Takahashi, F.W. Turek \& R.Y. Moore, pp. 1-28. Plenum Press, New York.

FROY, O. 2007. The relationship between nutrition and circadian rhythms in mammals. Frontiers in Neuroendocrinology 28: 61-71. 
GOLDMAN, B.D. 1999. The circadian timing system and reproduction in mammals. Steroids 64: 679-685.

HAIM, A. 1987.Thermoregulation and metabolism of Wagner's gerbil (Gerbillus dasyurus); a rock dwelling rodent adapted to arid and mesic environments. Journal of Thermal Biology 12: 45-48.

HAIM, A. \& TCHERNOV, E. 1974. The distribution of myomorph rodents in the Sinai Peninsula. Mammalia 32: 201-223.

HARRISON, D.L. \& BATES, P.J.J. 1991. The Mammals of Arabia, 2nd edn. Harrison Zoological Museum Publications, Harrison Zoological Museum, Sevenoaks, England.

KLAUS, U., WEINANDY, R. \& GATTERMANN, R. (2000) Circadian activity rhythms and sensitivity to noise in the Mongolian gerbil (Meriones unguiculatus). Chronobiology International 17: 137-145.

MACDONALD, D.W. (ed.) 2006. The Encyclopedia of Mammals, 2nd edn. Oxford University Press, Oxford.

MACFARLANE, W.V. 1968. Adaptation of ruminants to tropics and deserts. In: Adaptation of Domestic Animals, (ed.) E.S.E. Hafez, pp. 164-182. Lea and Febiger. Philidelphia, PA.

OKAMURA, H. YAMAGUCHI, S. \& YAGITA, K. 2002. Molecular machinery of the circadian clock in mammals. Cell Tissue Research 309: 47-56.

PITTENDRIGH, C.S. \& DAAN, S. 1974. Circadian oscillations in rodents: a systematic increase of their frequency with age. Science 186: 548-550.

PITTENDRIGH, C.S. \& DAAN, S. 1976. A functional analysis of circadian pacemakers in nocturnal rodents. VI. Entrainment: pacemaker as a clock. Journal of Comparative Physiology 106: 291-331.

PITTENDRIGH C.S. \& MINIS, D.H. 1964. The entrainment of circadian oscillations by light and their role as photoperiodic clocks. American Naturalist 98: 261-294.

QUINTERO, J.E., KUHLMAN, S.J. \& McMAHON, D.G 2003. The biological clock nucleus: a multiphasic oscillator network regulated by light. Journal of Neuroscience 23: 8070-8076.

REFINETTI, R. 2006. Circadian Physiology, 2nd edn. CRC Press/Taylor \& Francis Group, Boca Raton.

REFINETTI, R. 2007. Enhanced circadian photoresponsiveness after prolonged dark adaptation in seven species of diurnal and nocturnal rodents. Physiology $\mathcal{E}$ Behavior 90: 431-437.

SCHMIDT-NIELSEN,K. 1964. Desert Animals: Physiological Problems of Heat and Water. Oxford University Press, London.

SCHMIDT-NIELSEN, K. 1997. Animal Physiology: Adaptation and Environment. Cambridge University Press, Cambridge.

SKENE, D.J., LOCKLEY, S.W., THAPAN, K. \& ARENDT, J. 1999. Effects of light on human circadian rhythms. Reproduction, Nutrition E Development 39: 295-304.

STRAUSS, M., SHER KHAN, M. \& SHOBRAK, M. 2008. Rodent trapping in the Saja/Umm Ar-Rimth protected area of Saudi Arabia using two different trap types. Zoology in the Middle East 43: 31-39.

STEPHAN, F.K. \& ZUCKER, I. 1972. Circadian rhythms in drinking behavior and locomotor activity of rats are eliminated by hypothalamic lesions. Proceedings of the National Academy of Science U.S.A. 69: 1583-1586.

SZEISLER C.A., DUFFY, J.F., SHANAHAN, T.L. BROWN, E.N., MITCHELL,. J.F., RIMMER, D.W., RONDA, J.M., SILVA, E.J., ALLAN, J.S., EMENS, J.S., DIJK, D. \& KRONAUER, R.E. 1999. Stability, precision and near 24-hour period of the human circadian pacemaker. Science 284: 2177-2181.

WEINERT, D., WEINANDY, R \& GATTERMANN, R. 2007. Photic and non-photic effects on the daily activity pattern of Mongolian gerbils. Physiology $\mathcal{E}$ Behavior 90: 325-333.

ZAHAVI, A. \& WAHRMAN, J. 1957. The cytotaxonomy, ecology and evolution of the gerbils and jirds of Israel (Rodentia: Gerbillinae). Mammalia 21: 341-380.

Responsible Editor: A. Monadjem 